\title{
Laparoscopic-assisted repair of Morgagni hernia in children
}

\author{
Osama A. Bawazir ${ }^{1 *}$ (D) Anies Mahomed ${ }^{2}$, Amira Fayyad ${ }^{3}$, Elham Bagaryn ${ }^{3}$, Abdullah Bawazir $^{4}$ and Rahaf Mandora ${ }^{5}$
}

\begin{abstract}
Background: Morgagni hernia $(\mathrm{MH})$ is a rare diaphragmatic hernia with nonspecific symptoms and variable presentation. MH is managed surgically via laparotomy or a thoracotomy. Recently, laparoscopy was described for the repair of $\mathrm{MH}$. The objective of this study is to report our institutional experience in laparoscopic repair of $\mathrm{MH}$ in infants and children.

Results: Twenty-five patients with MH were included; 17 of them were males (68\%). Their median age at the time of diagnosis was 18 months. Sixteen patients (64\%) presented with a recurrent chest infection. MH was on the right side in 8 patients, left side in 2, and central in 12, and 3 patients had bilateral hernias. Eleven patients (44\%) had congenital heart disease, 10 (40\%) had Down's syndrome, and 2 (4\%) had malrotation of the bowel. The median size of the hernia defect was $3 \times 3.5 \mathrm{~cm}^{2}$, and the most common content was the colon $(n=19)$. One patient with Down's syndrome developed recurrence and underwent open repair. The median operative time was $95 \mathrm{~min}$. The postoperative recovery was uneventful, and the average postoperative stay was 3 days. The median follow-up was 4.5 years, and there was no reported mortality.
\end{abstract}

Conclusions: Morgagni hernia is commonly associated with other congenital anomalies. Laparoscopic repair of Morgagni hernia in children is feasible with excellent postoperative outcomes.

Keywords: Morgagni hernia, Laparoscopy, Post-sternotomy hernia

\section{Background}

Morgagni's hernia $(\mathrm{MH})$ is a retrosternal herniation of the abdominal contents through a diaphragmatic defect, and it presents $3-5 \%$ of all diaphragmatic hernias [1]. In most cases, the diaphragmatic defect is congenital in origin; however, it could be acquired as an incisional hernia after median sternotomy. Abdominal contents usually herniate on the right side in $90 \%$ of the patients [2], and the omentum is the most commonly reported herniated structure (60\%) [3].

In the pediatric age group, the presentation of congenital Morgagni's hernia is variable. The hernia can be discovered incidentally, or it can present with

\footnotetext{
* Correspondence: obawazir@yahoo.com; oabawazir@uqu.edu.sa

'Department of Surgery, Faculty of Medicine, Umm Al-Qura UniversityMakkah \& King Faisal Specialist Hospital \& Research Centre, P.O. Box 715, Mecca 21955, Kingdom of Saudi Arabia

Full list of author information is available at the end of the article
}

nonspecific gastrointestinal or respiratory symptoms and, in severe cases, with respiratory distress requiring support $[4,5]$. Because of the rarity of the condition, as well as the nonspecific presentation, the diagnosis is usually delayed. Patients typically have a chest X-ray as the initial diagnostic tool, and if the diagnosis of $\mathrm{MH}$ is suspected, further investigation with a barium study, computed tomography (CT) scan, or magnetic resonance imaging (MRI) is warranted, which additionally aid in defining the size and the content of the hernia sac [6].

The standard treatment of $\mathrm{MH}$ is surgical closure of the defect via laparotomy or thoracotomy. Currently, various laparoscopic techniques for the repair, including a primary closure of the defect with intracorporeal sutures, stapler, or a mesh, have been proposed [3]. Minimal invasive repair of $\mathrm{MH}$ has achieved satisfactory results with less trauma and earlier return to physical activity; however, the rate of complications is still high $[2$, 
7]. The objective of this study was to report the results of laparoscopic-assisted repair of Morgagni's hernia in infants and children in our institution.

\section{Methods}

\section{Data sources and study design}

This is a retrospective cohort study that included infants and children admitted to our hospital with the diagnosis of Morgagni's hernia from January 2005 to December 2019. A total of 25 infants with $\mathrm{MH}$ were presented to our center. Patients' data, including the age at presentation, sex, the presenting symptoms, radiological investigations, management, conversion to open surgery, and outcome of surgery, were retrieved from the medical charts. All patients had a laparoscopic-assisted repair of the $\mathrm{MH}$.

The study was approved by the Hospital Institutional Review Board (REF: SURG-J/520/40). Written informed consent was taken for the procedure, and verbal approval from the parents of enrolled children was taken during the procedure consent to use the data in research.

\section{Laparoscopic repair of Morgagni's hernia}

The repair of the MH was carried out under general anesthesia with endotracheal intubation. We positioned the patient in the supine position, and the legs were padded and protected. A folded towel was kept under the thighs to slightly flex the hip joint and prevent excessive stretching of the femoral nerve. The monitor was placed at the head end of the table towards the left side. The operating surgeon stood at the foot end, cameraman to the right, and nurse to the left. A nasogastric tube was inserted to decompress the stomach. Three ports were inserted; the first port was $5 \mathrm{~mm}$ and was inserted at the umbilicus using an open technique. A $30^{\circ}$ telescope was used in all cases. Carboperitoneum was maintained at 8 $\mathrm{mmHg}$, and the flow was set at $2 \mathrm{~L} / \mathrm{min}$. The patient was given an anti-Trendelenburg position to allow the bowel to move down towards the pelvis. A preliminary assessment was carried out to delineate the site and size of the defect and its contents. Two additional $3-5 \mathrm{~mm}$ ports were inserted on the left and right of the midline in the midclavicular line depending on the patient's size and instrument availability.

In most patients, the post-cardiac hernia was the most frequent type, and an anterior defect in the diaphragm spanning on both sides of the midline was visualized. The large bowel herniating through the defect could be easily reduced by using tension-free repair. The hernial sac was dissected free from the pericardium and pleura using gentle blunt dissection and excised, and usually, it was challenging to do so and one patient had the sac adherent to the pericardium. It is advised not to remove the sac because this can cause more damage to the pleura or the pericardium; therefore, if the sac was not removed, the edge of the defect was cauterized using a diathermy hook. The falciform ligament was passing either from the right side or posterior to the defect. The falciform ligament was divided in two patients $(8 \%)$ for better exposure of the defect. The falciform ligament was not cut routinely, only when interfering with the repair, particularly in bilateral $\mathrm{MH}$. When the content of the sac was liver, dissection was done using ligasure.

The edge of the diaphragm was sutured to the abdominal muscles with one of three methods: trans-fascial sutures with the knots residing in the subcutaneous plane, endo-fascial closer, or with a modified regular needle and passing it through the abdominal wall. A stab incision was made just below the sternum at the site of the diaphragmatic defect in the epigastric region. The type of sutures often used was Ethibond 2-0 suture material (Ethicon Inc. Cornelia, GA, USA), and Prolene was used in three patients (12\%) (Ethicon Inc. Cornelia, GA, USA). A horizontal mattress suture was taken, ensuring an adequate bite of the edge of the diaphragm at the site of the defect. This suture was then retrieved through the same incision. Four to five such sutures were inserted and held with hemostats. After placing all sutures, the carboperitoneum was reduced to $4 \mathrm{mmHg}$; the sutures were pulled upwards to even out the tension, and each one was tied. The knots of the tied sutures lay in the subcutaneous tissue. Gore-Tex mesh (W. L. Gore \& Associates, Inc. Flagstaff, AZ, USA) was required in four patients $(16 \%)$ using the same approach because of a large defect that could not be closed without tension ( $n$ $=3$ ) and for a recurrent case $(n=1)$.

\section{Statistical analysis}

Continuous variables were presented as median and 25th and 75th percentile or range when appropriate and categorical variables as number and its percentage. Mann-Whitney test was used to test the significant difference in continuous outcomes. All analyses were performed using Stata 14.2 (StataCorp, College Town, TX, USA)

\section{Results}

Twenty-five patients with Morgagni hernia were presented to our hospital during the study period. Their demographics and preoperative data are summarized in Table 1 . Their age at the time of diagnosis ranged from 28 days to 9 years (median, 18 months).

Recurrent chest infection was the most common presenting symptom $(n=16 ; 64 \%)$. One patient presented at the age of 18 months with poor feeding, vomiting, and tachycardia, the chest X-ray was highly suggestive of 
Table 1 Preoperative patients' characteristics

\begin{tabular}{ll}
\hline Variable & $(n=25)$ \\
\hline Age (months) & $18(15-24)$ \\
Male n (\%) & $17(68 \%)$ \\
Site of the hernia & \\
Bilateral & $3(12 \%)$ \\
Central & $13(52 \%)$ \\
Right & $2(8 \%)$ \\
Left & $7(28 \%)$ \\
Content of the hernial sac & \\
Colon & $19(76 \%)$ \\
liver & $3(12 \%)$ \\
Omentum & $3(12 \%)$ \\
Major associated lesions & \\
Congenital heart disease & $11(44 \%)$ \\
Down Syndrome & $10(40 \%)$ \\
Bowel Malrotation & $2(4 \%)$ \\
\hline
\end{tabular}

$\mathrm{MH}$, and the diagnosis was confirmed with a computed tomographic (CT) scan.

Three patients had bilateral Morgagni hernia on the CT scan of the chest, and this was confirmed during the surgery (Table 1). In all patients with Morgagni hernia, the diagnosis was suspected on chest X-ray, especially on a lateral view, then confirmed by CT scan (Figs. 1 and 2).

Associated anomalies were seen in 23 (92\%) patients (Table 1). The median size of the hernial defect was $3 \times$ $3.5 \mathrm{~cm}^{2}$. All patients had a laparoscopic-assisted repair of the hernia (Fig. 3). The median operative time was 95 min (25th and 75th percentile, 89 and $117 \mathrm{~min}$ ), and operative time did not differ significantly in patients who had prior cardiac surgery $(p=0.38)$ or those with Down's syndrome $(p=0.65)$. Gore-Tex mesh was used in 4 patients (16\%); none of them had a recurrence; however, one had postoperative pericardial effusion, which resolved spontaneously after 3 days. The postoperative chest $\mathrm{X}$-rays were normal, and feeding was started after $6 \mathrm{~h}$ in all patients. The postoperative

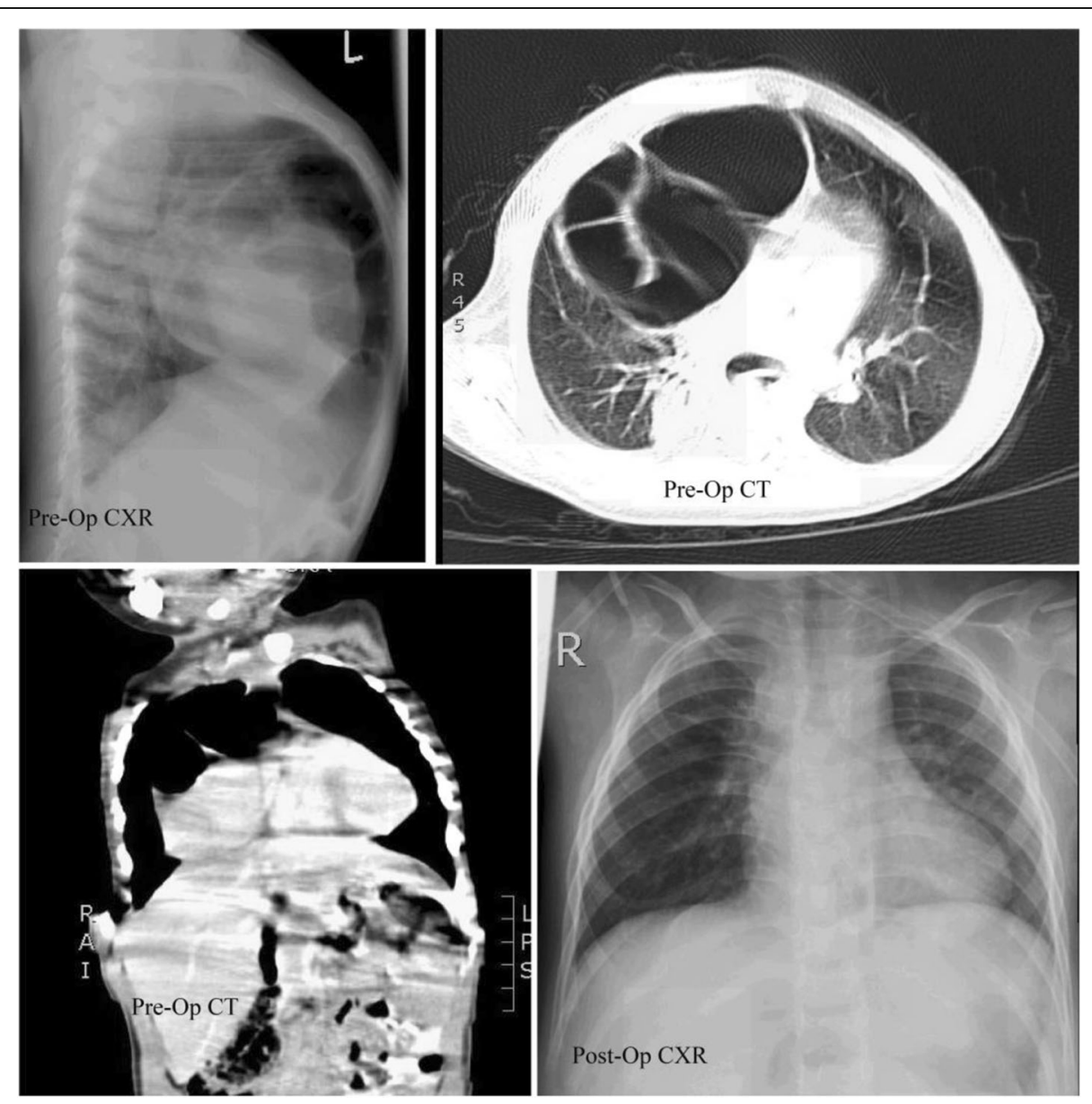

Fig. 1 a) Lateral chest $x$-ray of a case of Morgagni hernia. $\mathbf{b}$ and $\mathbf{c}$ ) $C T$ chest showing herniation of the colon on the right side. $\mathbf{d}$ ) Postoperative chest $x$-ray with the hernia reduced 

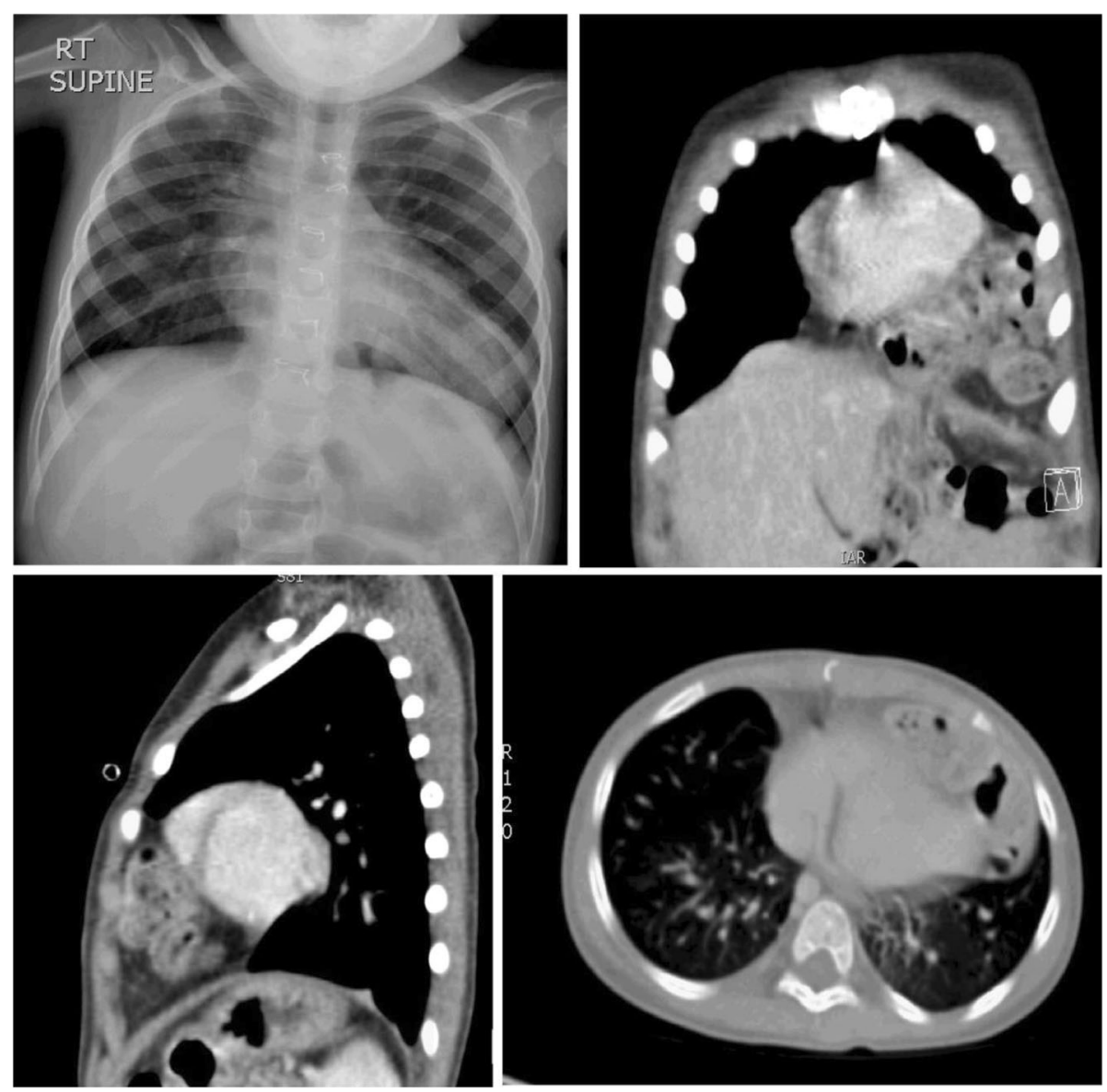

Fig. 2 a) Posteroanterior chest x-ray with left side Morgagni hernia. b, c, and d) CT chest showing left-side Morgagni hernia with colonic herniation

recovery was uneventful without any incidence of atelectasis or other postoperative complications. Mild pericardial effusion was reported in one patient (4\%). The average postoperative stay was 3 days. The median follow-up was 4.5 years (25th and 75th percentile, 3 and 6.5 years). One patient with post-cardiac surgery hernia sized $4 \times 4 \mathrm{~cm}$ and Down's syndrome developed recurrence and underwent repair using the open approach. There was no operative or long-term mortality.

\section{Discussion}

Morgagni hernia is a rare type of the diaphragmatic hernias in which the hernia defect is formed because of the failure of the fusion of sternal and costal parts of the diaphragm [8]. In our series, $10(40 \%)$ of the patients had Down's syndrome, and 11 (44\%) had congenital heart disease and presented after surgical correction via median sternotomy. The high number of patients presented after cardiac surgery could be related to the nature of our hospital as a tertiary care center. Moreover, chest drains inserted in the substernal area post-cardiac surgery may lead to poor tissue healing in this area and contribute to the increased incidence of Morgagni hernia after cardiac surgery. Additionally, tissue healing is further impaired in Down's syndrome due to altered cellular immunity [9], and the association between $\mathrm{MH}$ and Down's syndrome has previously described [7, 10, 11] Six of our patients have Down's syndrome and $\mathrm{MH}$ without previous sternotomy.

Morgagni hernias are mostly small and asymptomatic, and they are diagnosed incidentally on chest radiographs $[12,13]$. MH may present with nonspecific gastrointestinal or respiratory symptoms and rarely with severe respiratory distress, cardiac tamponade, bowel strangulation or perforation, and gastric volvulus. Chest radiography is usually the first diagnostic tool, and in suspected cases, the diagnosis is confirmed with other modalities. A CT scan is the most common diagnostic tool utilized in our series, and it has the advantages of imaging the defect and evaluating the extent of the sac and its content.

Surgical treatment is the preferred modality to avoid $\mathrm{MH}$ complications such as strangulation, despite its rarity. The standard surgical procedure can be performed 

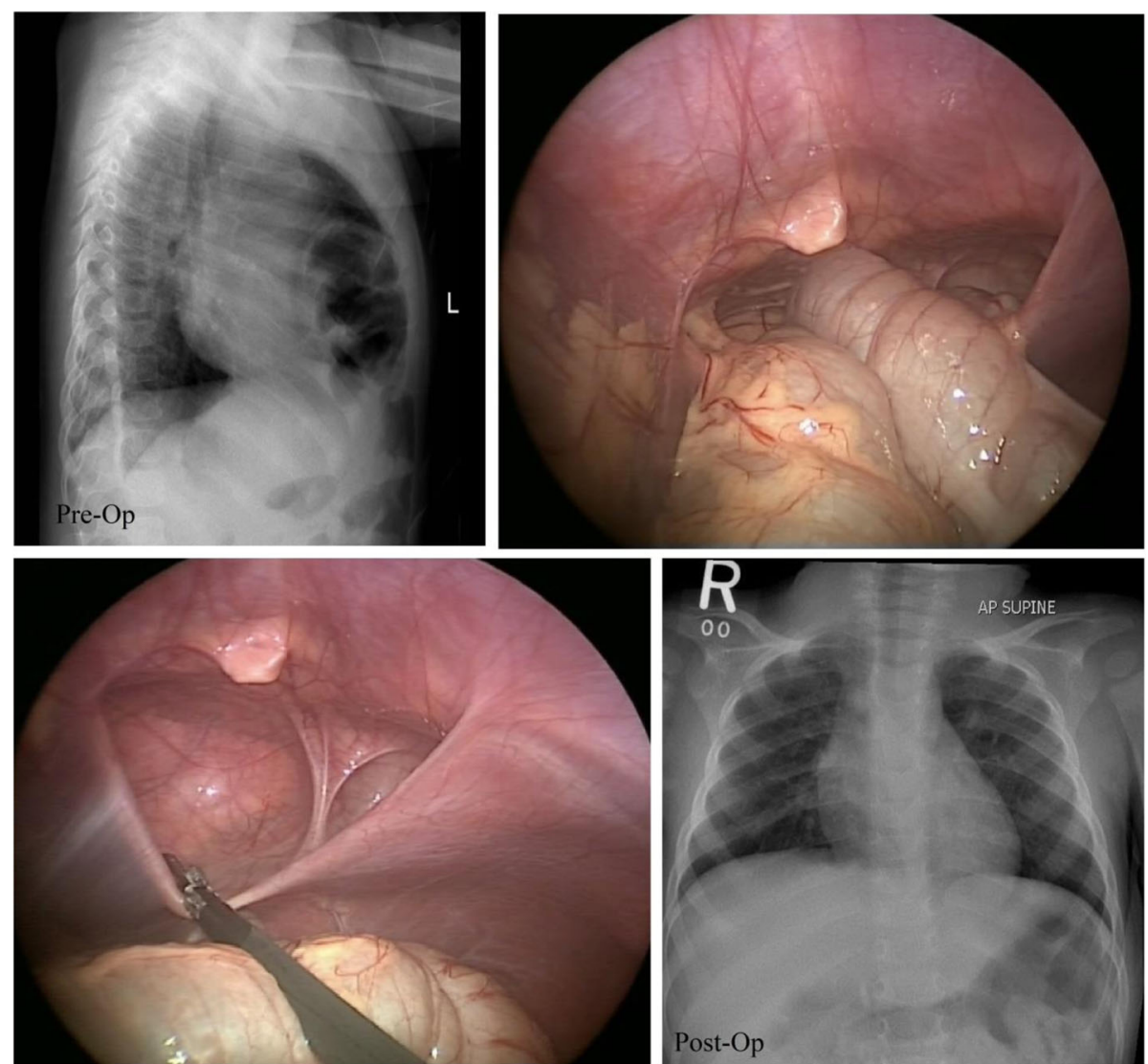

Fig. 3 a) Preoperative chest $x$-ay with Morgagni hernia b) laparoscopic view with colonic herniation. c) Laparoscopic view of the defect after cutting the adhesions. d) Postoperative chest $x$-ray

to close the defect with or without mesh, either transabdominal or trans-thoracic, and both approaches can be either open or endoscopic [14]. With the recent advances in minimally invasive surgery, laparoscopy became the preferred approach in children with $\mathrm{MH}$ [15]. Defects can be closed primarily, or in case of large defects, a mesh can be used [3]. The laparoscopic approach has several advantages in addition to the cosmetic results, including early feeding and ambulation, less pain, and shorter hospital stay [16]. There are several methods of laparoscopic repair, some investigators described total intracorporeal repair [17], while others recommended transabdominal sutures with extracorporeal knots with comparable results. Unfortunately, there are no randomized clinical trials to compare both approaches.

The use of synthetic patch during the primary repair was recommended by some authors to avoid tension $[18,19]$, and a high rate of recurrence after laparoscopic $\mathrm{MH}$ repair was reported if a patch was not used [20]. The use of synthetic patch becomes mandatory in case of large defects and when significant tension is expected after the primary repair. Four of our patients required
Gore-Tex mesh to prevent tension after repairing large defects.

The excision of the hernia sac in $\mathrm{MH}$ remains controversial. Fernandez-Cebrian and De Oteyza [21] and Rau and their groups [22] recommended removal of the hernia sac, whereas others prefer to leave the hernia sac in situ [23, 24] This is a crucial step that needs to be done with the utmost care and gentleness to avoid pleural or pericardial injury. We routinely excise the hernia sac in $\mathrm{MH}$ because we believe this reduces the chances of recurrence. We try to remove the sac if it is technically feasible; however, if it is adherent or thick, it is better to leave it and cauterize the edges. We had experience in one case in which the sac was adherent to the pericardium and resulted in making a large pericardial window that required a Gore-Tex patch, and the patient had postoperative pericardial effusion which resolved spontaneously after 3 days.

\section{Study limitations}

The major limitation of the study is the retrospective nature with its inherited referral and selection biases, but 
this study design is accepted when dealing with rare diseases. Another limitation is the single-center experience, and generalization of the results may be an issue. However, this study reports an extensive experience in the laparoscopic repair of $\mathrm{MH}$ over 15 years in the pediatric population.

\section{Conclusion}

Morgagni's hernia is a rare form of diaphragmatic hernias which could be congenital or acquired after cardiac surgery. MH is frequently associated with other anomalies such as congenital heart disease and Down's syndrome. Because of the nonspecific symptoms, the condition should be suspected in infants with a repeated chest infection. Laparoscopic repair is a relatively simple and effective technique of repair in children with decreased morbidity; an earlier return to physical activity and recurrence is uncommon.

\section{Abbreviations}

MH: Morgagni hernia; CT: Computed tomography scan; MRI: Magnetic resonance imaging

\section{Acknowledgements \\ I would like to express my deep gratitude to Miss Razan Bawazir for her valuable support on the photo editing in this article.}

\begin{abstract}
Authors' contributions
$O B$ and $A M$ made the study design. $A B$ and RM did the extensive literature review and analyzed and interpreted the patient data regarding Morgagni's hernia in children. AF and EB performed the data collection and was a major contributor in writing the manuscript. $O B$ and $A M$ supervised all other junior authors and did the final revision and correction of the manuscript. All authors contributed to the conception or design of the work and/or the acquisition, analysis, and interpretation of data. Drafts were revised critically for important intellectual content, and the final version was approved by all. All agreed to be accountable for all aspects of the work and have read and approved the final manuscript.
\end{abstract}

\section{Funding}

None

\section{Availability of data and materials}

The datasets generated and/or analyzed during the current study are not publicly available due [patient confidentiality policy in our institution] but are available from the corresponding author on reasonable request.

\section{Ethics approval and consent to participate}

All procedures performed in studies involving human participants were in accordance with the ethical standards of the institutional and/or national research committee and with the 1964 Helsinki declaration and its later amendments or comparable ethical standards. Approval of research protocol IRB 2019-24: LAPAROSCOPIC MANAGEMENT MORGAGNI HERNIA IN CHILDREN SURG-J/520/40 was given by Institution Review Board (IRB)-Research center department at King Faisal Specialist Hospital and Research Centre (KFSH\&RC) - Jeddah Branch. Verbal consent was obtained from the parents of all patients included in the study.

\section{Consent for publication}

Written informed consent for the publication of this data was given by the patients' parents or their legal guardians.

\section{Competing interests}

Author $\mathrm{OB}$ declares that he has no conflict of interest.

\section{Author details}

'Department of Surgery, Faculty of Medicine, Umm Al-Qura UniversityMakkah \& King Faisal Specialist Hospital \& Research Centre, P.O. Box 715, Mecca 21955, Kingdom of Saudi Arabia. ${ }^{2}$ King Faisal Specialist Hospital and Research Centre, P O Box 40047, Jeddah 21499, Kingdom of Saudi Arabia. ${ }^{3}$ Batterjee Medical College, Jeddah, Kingdom of Saudi Arabia. ${ }^{4}$ College of Medicine-Jeddah, College Of Medicine, King Saud Bin Abdulaziz University for Health Sciences, Jeddah, Mecca, Kingdom of Saudi Arabia. ${ }^{5}$ Faculty of Medicine, Umm Al-Qura University, P.O. Box 715, Mecca 21955, Kingdom of Saudi Arabia.

Received: 2 October 2019 Accepted: 1 April 2020

Published online: 23 April 2020

\section{References}

1. Shah RS, Sharma PC, Bhandarkar DS. Laparoscopic repair of Morgagni's hernia: an innovative approach. J Indian Associ Pediatr Surgeons. 2015 Apr; 20(2):68.

2. Al-Salem AH. Congenital hernia of Morgagni in infants and children. J Pediatr Surg. 2007;42(9):1539-43.

3. Al-Salem AH, Zamakhshary M, Al Mohaidly M, Al-Qahtani A, Abdulla MR, Naga MI. Congenital Morgagni's hernia: a nationalmulticenter study. J Pediatr Surg. 2014;49(4):503-7.

4. Nasr A, Fecteau A. Foramen of Morgagni hernia: presentation and treatment. Thorac Surg Clin. 2009;19(4):463-8.

5. Mallick MS, Alqahtani A. Laparoscopic-assisted repair of Morgagni hernia in children. J Pediatr Surg. 2009;44(8):1621-4.

6. Rattan KN, Singh J, Dalal P. Childhood Morgagni hernia: report of two cases. JPNIM. 2017;6(1):e060114.

7. Akkoyun I, Kececioglu M. A new, easy and safe suturing technique for laparoscopic repair of Morgagni hernia. J Pediatr Surg. 2012;47: 1626-8.

8. Ipek T, Altinli E, Yucelar S, et al. Laparoscopic repair of a Morgagni-Larrey hernia: report of three cases. Surg Today. 2002;32(10):902-5.

9. Spina CA, Smith D, Korn E, Fahey JL, Grossman HJ. Altered cellular immune functions in patients with Down syndrome. Am J Dis Child. 1981;135(3): 251-5.

10. Parmar RC, Tullu MS, Bavdekar SB, Borwankar SS. Morgagni hernia with Down syndrome: a rare association - case report and review of literature. J Postgrad Med. 2001;47(3):188-90.

11. Cigdem MK, Onen A, Okur H, Otcu S. Associated malformations in Morgagni hernia. Pediatr Surg Int. 2007;23(11):1101-3.

12. Papia G, Gerstele JT, Langer JC. Laparoscopic repair of Morgagni diaphragmatic hernia in children: Technical challenges and results. Pediatr Endosurg Innov Tech 2004; 8:245-249.

13. Estevaio-Costa J, Soares-Oliveira M, Correia-Pinto J, et al. Acute gastric volvulus secondary to a Morgagni hernia. Paediatr Surg Int. 2000;16:107-8

14. Azzie G, Maoate K, Beasley S, et al. A simple technique of laparoscopic fullthickness anterior abdominal wall repair of retrosternal (Morgagni) hernias. J Pediatr Surg. 2003;38:768-70.

15. Aydin $Y$, Altuntas B, Ulas AB, Dahai C, Eroglu A. Morgagni hernia: transabdominalor transthoracic approach? Acta Chir Belg. 2014;114: 131-5.

16. Laituri CA, Garey CL, Ostlie DJ, Holcomb GW, St Peter SD. Morgagni hernia repair in children: comparison of laparoscopic and open results. J Laparoendosc Adv Surg Tech A. 2011;21:89-91.

17. Durak E, Gur S, Cokmez A, Atahan K, Zahtz E, Tarcan E. Laparoscopic repair of Morgagni hernia. Hernia. 2007;11(3):265-70.

18. Dutta S, Albanese CT. Use of prosthetic patch for laparoscopic repair of Morgagni diaphragmatic hernia in children. J Laparoendosc Adv Surg Tech A. 2007;17(3):391-4

19. Tan YW, Banerjee D, Cross KM, De Coppi P, Blackburn SC, Rees CM, et al. Morgagni hernia repair in children over two decades: Institutional experience, systematic review, and meta-analysis of 296 patients. J Pediatr Surg. 2018:S0022-3468(18)30248-3.

20. Garriboli M, Bishay M, Kiely EM, et al. Recurrence rate of Morgagni diaphragmatic hernia following laparoscopic repair. Pediatr Surg Int. 2013; 29:185-9.

21. Fernandez-Cebrian JM, De Oteyza JP. Laparoscopic repair of hernia of foramen of Morgagni: a new case report. J Laparoendosc Surg. 1996;6:61-4. 
22. Rau HG, Schardey HM, Lange V. Laparoscopic repair of Morgagni hernia. Surg Endosc. 1994:8:1439-42.

23. Huntington TR. Laparoscopic transabdominal pre peritoneal repair of hernia of Morgagni. J Laparoendosc Surg. 1996;6:131-3.

24. Orita M, Okino M, Yamashita K, Morita N, Esata K. Laparoscopic repair of a diaphragmatic hernia through foramen of Morgagni. Surg Endosc. 1997;11: 668-70

\section{Publisher's Note}

Springer Nature remains neutral with regard to jurisdictional claims in published maps and institutional affiliations.

\section{Submit your manuscript to a SpringerOpen ${ }^{\mathcal{O}}$ journal and benefit from:}

- Convenient online submission

- Rigorous peer review

- Open access: articles freely available online

- High visibility within the field

- Retaining the copyright to your article

Submit your next manuscript at $\boldsymbol{\sim}$ springeropen.com 